\title{
Characterization of Halomonas sp. ZM3 isolated from the Zelazny Most post-flotation waste reservoir, with a special focus on its mobile DNA
}

\author{
Lukasz Dziewit ${ }^{1}$, Adam Pyzik ${ }^{1}$, Renata Matlakowska ${ }^{2}$, Jadwiga Baj ${ }^{1}$, Magdalena Szuplewska ${ }^{1}$ and Dariusz Bartosik ${ }^{1 *}$
}

\begin{abstract}
Background: Halomonas sp. ZM3 was isolated from Zelazny Most post-flotation mineral waste repository (Poland), which is highly contaminated with heavy metals and various organic compounds. Mobile DNA of the strain (i.e. plasmids and transposons) were analyzed in order to identify genetic information enabling adaptation of the bacterium to the harsh environmental conditions.

Results: The analysis revealed that ZM3 carries plasmid pZM3H1 (31,370 bp), whose replication system may be considered as an archetype of a novel subgroup of IncU-like replicons. pZM3H1 is a narrow host range, mobilizable plasmid (encodes a relaxase of the MOB $\mathrm{B}_{\mathrm{v}}$ family) containing mercury resistance operon (mer) and czcD genes (mediate resistance to zinc and cobalt), which are part of a large truncated Tn3 family transposon. Further analysis demonstrated that the phenotypes determined by the $\mathrm{pZM} 3 \mathrm{H} 1$ resistance cassette are highly dependent on the host strain. In another strand of the study, the trap plasmid PMAT1 was employed to identify functional transposable elements of Halomonas sp. ZM3. Using the sacB positive selection strategy two insertion sequences were identified: ISHsp I - representing IS5 group of IS5 family and ISHsp2 - a distinct member of the IS630 family.

Conclusions: This study provides the first detailed description of mobile DNA in a member of the family Halomonadaceae. The identified IncU plasmid pZM3H1 confers resistance phenotypes enabling adaptation of the host strain to the Zelazny Most environment. The extended comparative analysis has shed light on the distribution of related IncU plasmids among bacteria, which, in many cases, reflects the frequency and direction of horizontal gene transfer events. Our results also identify plasmid-encoded modules, which may form the basis of novel shuttle vectors, specific for this group of halophilic bacteria.
\end{abstract}

Keywords: Halomonas sp., Mobile genetic elements, IncU plasmid, Transposable elements, Heavy metal resistance, Bacterial adaptation

\section{Background}

The Zelazny Most surface waste management system is the largest mineral waste repository in Europe and one of the largest in the world. It is located in the LubinGlogow Copper District in southwest Poland and covers an area of $13.94 \mathrm{~km}^{2}$. Polymetallic organic-rich copper ore is currently mined underground in this area. This ore is characterized by its neutral or slightly alkaline $\mathrm{pH}$ (of up to 8.5 ) and its high salinity.

\footnotetext{
* Correspondence: bartosik@biol.uw.edu.pl

'University of Warsaw, Faculty of Biology, Institute of Microbiology,

Department of Bacterial Genetics, Miecznikowa 1, 02-096, Warsaw, Poland

Full list of author information is available at the end of the article
}

Zelazny Most reservoir was built in 1974 to collect flotation tailings from three local copper-ore enrichment facilities, for the storage of groundwater from the LubinGlogow mines, and to be used to facilitate flotation of sulfides during ore processing and transport of the gangue. The total volumes of wastes and water present in Zelazny Most are estimated to be $476 \mathrm{mln} \mathrm{m}^{3}$ and $7.5 \mathrm{mln} \mathrm{m}^{3}$, respectively. The annual deposition of flotation tailings varies from 20 to 26 million tons [1].

The deposits in Zelazny Most have an alkaline $\mathrm{pH}$ (8.5) and are highly contaminated with heavy metals $(\mathrm{Cu}, \mathrm{Pb}$, $\mathrm{As}, \mathrm{Ni}, \mathrm{Co}, \mathrm{Zn}$ and $\mathrm{Cr}$ ) and various organic compounds, including polycyclic aromatic hydrocarbons (PAH) such as anthracene, biphenyl, dibenzofurane, dibenzothiophene,

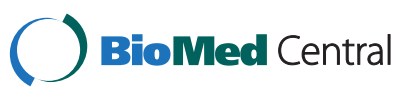


chrysene, fluoranthene, fluorene, naphthalene, methylnaphthalene, methylphenanthrene, phenanthrene and pyrene ([2] and unpublished data). Zelazny Most is located in a seismically active area; however the seismicity is not a natural phenomenon, but is induced by the mining works in the nearby underground copper mines. This seismic activity could lead to the release of the contents of Zelazny Most to the environment, which would have devastating consequences [3].

The water stored in Zelazny Most is of the $\mathrm{Cl}_{-} \mathrm{SO}_{4-}$ $\mathrm{Na}-\mathrm{Ca}$ type with mineralization levels of up to 21,400 $\mathrm{mg} \mathrm{l}^{-1}$. The respective concentrations of sodium $\left(\mathrm{Na}^{+}\right)$ and chlorine $\left(\mathrm{Cl}^{-}\right)$ions are up to $4500 \mathrm{mg} \mathrm{l}^{-1}$ and around $8000 \mathrm{mg} \mathrm{l}^{-1}$, which makes this environment extremely salty [4]. Saline environments are inhabited by specialized microorganisms, typically halophilic Archaea (e.g. Halobacteriaceae) and Bacteria (e.g. Halomonadaceae).

The family Halomonadaceae (Oceanospirillales, Gammaproteobacteria) currently is comprised of 9 genera. These are chemoorganoheterotrophic, aerobic or facultatively anaerobic bacteria, most of which are halophilic or halotolerant. The genus Halomonas (type species H. elongata, isolated in 1980) contains over forty named species. Members of the Halomonas genus have a respiratory-type metabolism with oxygen as the terminal electron acceptor, although some can use nitrate as an alternative acceptor under anaerobic growth conditions. These bacteria are prototrophs able to utilize a large range of organic compounds as their sole carbon and energy source (e.g. carbohydrates, amino acids, polyols, hydrocarbons). The majority of them require $\mathrm{Na}^{+}$ions for growth $(0.1-0.3 \%)$ and all can grow in a broad range of $\mathrm{NaCl}$ concentrations (0.1-32.5\%) [5]. Halomonads may be isolated from various saline environments, regardless of their geographical location (e.g. marine environments, saline lakes and soils, intertidal estuaries, solar salt facilities, salty foods). Four species were isolated from the rhizosphere of xerophytic plants [6].

Extreme halophiles, including halomonads, are sources of a variety of bioproducts that can function under conditions of high salt: (i) compatible solutes that have a stabilizing and protective effect on biomolecules, cell structures and whole cells, (ii) extracellular enzymes adapted to saline stress, (iii) biosurfactants, (iv) extracellular polysaccharides and (v) poly- $\beta$-hydroxyalcanoates. The use of halophiles in the production of these compounds can significantly lower the cost of fermentation and recovery processes, since high salt concentrations reduce the possibility of contamination by non-halophilic microorganisms, thus, the energy requirement for sterilization can be significantly decreased $[7,8]$.

In recent years, several Halomonas spp. genomic projects were initiated, but so far only the genome of the ectoine producer Halomonas elongata DSM 2581 has been completed [9]. Current knowledge of mobile genetic elements (MGEs) of halomonads is also very poor. Several Halomonas spp. plasmids have been described, but only the narrow-host-range (NHR), mobilizable, cryptic plasmid pHE1 $(4.2 \mathrm{~kb})$ of the moderately halophilic bacterium $H$. elongata ATCC 33174 has been characterized in detail $[10,11]$. In addition, a temperate phage PhiHAP-1, which possesses a linear plasmid-like prophage genome, was isolated from Halomonas aquamarina and sequenced [12].

In this study, we have analyzed strain Halomonas sp. ZM3, isolated from Zelazny Most during the Bioshale project (a part of this project was to identify microbiological consortia useful in mineral processing) [13]. We have performed complex structural and functional analyses of mobile genetic elements of this strain, specifically plasmid pZM3H1, responsible for adaptation of the host strain to the harsh environment and two insertion sequences (ISs) captured using the trap plasmid pMAT1. To our knowledge this is the first description of functional transposable elements in halomonads.

\section{Methods}

\section{Bacterial strains, plasmids and culture conditions}

The strain ZM3 was isolated from a sample of the flotation tailings of Zelazny Most (Poland). The sample $(10 \mathrm{~g})$ was resuspended in $20 \mathrm{ml}$ of sterile salt solution $(0.85 \% \mathrm{NaCl})$, shaken at $22^{\circ} \mathrm{C}$ for $2 \mathrm{~h}$ and streaked onto the solid LB medium. Plates were incubated at $22^{\circ} \mathrm{C}$ for 1-2 weeks. The isolated strain was classified as a member of the Halomonas genus by $16 \mathrm{~S}$ rDNA sequence similarity. Other bacterial strains used in this study were (i) Eschericha coli TG1 [14], (ii) E. coli BR825 [15], (iii) Agrobacterium tumefaciens LBA288 [16], (iv) Paracoccus versutus UW225 [17], (v-xv) Alcaligenes sp. LM16R, Halomonas sp. ZM3R, Pseudomonas spp. - strains LM5R, LM6R, LM7R, LM8R, LM11R, LM12R, LM13R, LM14R, LM15R (rifampin resistant derivatives of wildtype strains isolated from Lubin copper mine).

The following plasmid vectors were used: (i) pABW1 (Km ${ }^{\mathrm{r}}$; ori $\mathrm{pMB1}$; oriT RK2) [18], (ii) pBBR1-MCS2 ( $\mathrm{Km}^{\mathrm{r}}$; ori $\mathrm{pBBR} 1$; broad-host-range cloning vector; oriT RK2) [19] and (iii) pMAT1 $\left(\mathrm{Km}^{\mathrm{r}}\right.$; ori pBBR1; oriT RK2; sacB; trap plasmid) [20]. Plasmids constructed in this work were: (i) pABW-ZM3H1 $\left(\mathrm{Km}^{\mathrm{r}}\right.$; ori $\mathrm{pMB1}$; ori $\mathrm{pZM} 3 \mathrm{H} 1$; oriT RK2) - mobilizable E. coli-Halomonas spp. shuttle plasmid constructed by insertion of an EcoRV restriction fragment of pZM3H1 (containing the plasmid replication system) into the BamHI site of pABW1 (BamHI 5' overhangs filled with Klenow fragment of DNA polymerase I), and (ii) pBBR-ZM3CZCMER ( $\mathrm{Km}^{\mathrm{r}}$; ori pBBR1; oriT RK2) - EcoRI-NheI restriction fragment of pZM3H1, containing resistance determinants, inserted between the SmaI and EcoRI sites of pBBR1MCS-2 
(NheI 5 overhang filled with Klenow fragment of DNA polymerase I).

Bacterial strains were grown in LB (lysogeny broth) medium [21] or mineral basal salts (MBS) medium [22] at $37^{\circ} \mathrm{C}$ (E. coli) or $30^{\circ} \mathrm{C}$ (other strains). Where necessary, the medium was supplemented with kanamycin $(50 \mu \mathrm{g} / \mathrm{ml})$, rifampin $(50 \mu \mathrm{g} / \mathrm{ml})$ and sucrose $(10 \%)$.

\section{Temperature, $\mathrm{pH}$ and salinity tolerance analyses}

The temperature, $\mathrm{pH}$ and salinity tolerance of Halomonas sp. ZM3 were analyzed by monitoring changes in optical density (in comparison with non-inoculated controls) during incubation of cultures in titration plates, with the aid of an automated microplate reader (Sunrise, TECAN). Overnight cultures were diluted in fresh LB media with adjustments for the separate assays: (i) $\mathrm{pH} 7.0$ for the temperature tolerance analysis, (ii) $\mathrm{pH} 2.0-13.0$ for the $\mathrm{pH}$ tolerance analysis, or (iii) supplemented with $\mathrm{NaCl}$ to final concentrations of $0.5 \%, 3 \%, 6 \%, 9 \%, 12 \%$ or $15 \%$. In each case, the initial optical density at $600 \mathrm{~nm}\left(\mathrm{OD}_{600}\right)$ was 0.05 . The microplates were then incubated with shaking at $30^{\circ} \mathrm{C}$ (for $\mathrm{pH}$ and salinity tolerance analysis) or $4^{\circ} \mathrm{C}, 15^{\circ} \mathrm{C}$, $22^{\circ} \mathrm{C}, 25^{\circ} \mathrm{C}, 30^{\circ} \mathrm{C}, 37^{\circ} \mathrm{C}, 42^{\circ} \mathrm{C}$ or $50^{\circ} \mathrm{C}$ (for temperature tolerance analysis) for 48 hours.

\section{Utilization of polycyclic aromatic hydrocarbons}

To test the ability of bacterial strains to utilize anthracene, phenanthrene, fluoranthene, fluorene and pyrene, the modified PAH plate assay was employed [23,24]. A volume of $5 \mu \mathrm{l}$ of each overnight culture was spotted onto the surface of an MBS agar plate and allowed to soak in. Bacterial cultures were pre-grown for 48 hours and then flooded with $1 \mathrm{ml}$ of a $1 \%(\mathrm{w} / \mathrm{v})$ solution of each PAH dissolved in acetone. After evaporating the acetone, the plates were incubated at $30^{\circ} \mathrm{C}$ for up to 2 weeks and inspected daily for the presence of a clear zone surrounding the area of growth (scored positive).

\section{Heavy metal and metalloid ion resistance}

Analytical grade heavy metal salts $\left(3 \mathrm{CdSO}_{4} \times 8 \mathrm{H}_{2} \mathrm{O}\right.$, $\mathrm{CoSO}_{4} \times 7 \mathrm{H}_{2} \mathrm{O}, \mathrm{CuSO}_{4}, \mathrm{HgCl}_{2}, \mathrm{~K}_{2} \mathrm{Cr}_{2} \mathrm{O}_{7}, \mathrm{NaAsO}_{2}$, $\left.\mathrm{Na}_{2} \mathrm{HAsO}_{4} \times 7 \mathrm{H}_{2} \mathrm{O}, \mathrm{NiCl}_{2} \times 6 \mathrm{H}_{2} \mathrm{O}, \mathrm{ZnSO}_{4} \times 7 \mathrm{H}_{2} \mathrm{O}\right)$ were used to prepare $0.01 \mathrm{M}, 0.1 \mathrm{M}$ and $1 \mathrm{M}$ stock solutions in water. Each solution was filter-sterilized and added to LB medium to produce a range of final concentrations (33 separate dilutions) of between $0.01 \mathrm{mM}$ and $100 \mathrm{mM}$ of the metal ion. Minimum inhibitory concentrations (MICs) for all analyzed strains were defined on titration plates using a broth dilution method in which changes in the optical density of cultures were measured in comparison with non-inoculated controls. Each microplate was monitored for growth using an automated microplate reader at 24-hour intervals for three days.
The heavy metal resistance phenotype was assessed from the ability to grow in the presence of (i) $10 \mathrm{mM}$ As (V), (ii) $1 \mathrm{mM}$ each of $\mathrm{As}(\mathrm{III}), \mathrm{Cd}, \mathrm{Co}, \mathrm{Cu}, \mathrm{Ni}, \mathrm{Zn}$ and $\mathrm{Cr}$, and (iii) $0.1 \mathrm{mM} \mathrm{Hg}[25,26]$.

\section{Beta-lactams resistance}

The MICs of antibiotics representing three classes of betalactams were determined by Epsilometer tests (E-tests, OXOID) using a gradient of the appropriate antibiotic: ampicillin (a penicillin), ceftazidime (a cefalosporin) and meropenem (a carbapenem). Each E-test strip was placed on lawns of the bacteria on agar plates and the pattern of growth was recorded after 48 hours incubation at $30^{\circ} \mathrm{C}$ or $37^{\circ} \mathrm{C}$. The lowest concentration of the antibiotic that prevented growth was considered the MIC.

\section{Siderophore detection}

The ability to produce siderophores was examined using the modified chrome azurol S (CAS) agar plate method [27]. Plates were incubated at $30^{\circ} \mathrm{C}$ for 72 hours in the dark and the formation of halos around colonies was recorded.

\section{Plasmid DNA isolation, genetic manipulations, PCR conditions and introduction of plasmid DNA into bacterial cells}

The isolation of plasmids, Southern hybridization analysis and common DNA manipulation methods were performed as described by Sambrook and Russell [21]. PCR was performed in a Mastercycler (Eppendorf) using HiFi polymerase (Qiagen; with supplied buffer), dNTP mixture and total DNA of Halomonas sp. ZM3 with appropriate primer pairs: (i) LISPHSP1 (5'-GATAAGCGCCAGG CACCACA-3') and RISPHSP1 (5'-TCGGCGAGCTTCCT CAGAAC-3') - specific to ISHsp1; (ii) LISPHSP2 (5'-TGTC CTCCGCCTATCACCAC-3') and RISPHSP2 (5'-ACGGCA GCCATGCGTACTTC-3') - specific to ISHsp2; (iii) LCZC ZM3 (5'-GATGCGCTCACCTCTGTATT-3') and RCZC ZM3 (5'-CACAAGTGATGCGTTATCCG-3') - specific to the cobalt, zinc, cadmium (CZC) resistance module (orf1112) of plasmid pZM3H1; and (iv) LMERZM3 (5'-GCGG AACCTGCGTCAACATT-3') and RMERZM3 (5'-GGCC ATCACAGCAGTCTGAA-3') - specific to the mercury (MER) resistance module (merA, orf19) of pZM3H1. The $s a c B$-specific primers used to identify the target site of transposition, were previously described by Szuplewska and Bartosik [20]. A colony PCR method for the amplification of 16S rRNA genes [28], used primers $27 \mathrm{f}$ and 1492r [29]. The transformation of E. coli strains was performed according to the method of Kushner [30]. Triparental mating was performed as described previously [31]. 


\section{Identification and analysis of a pool of TEs}

Trap plasmid pMAT1 [20], containing sacB of Bacillus subtilis, was introduced into Halomonas sp. ZM3R. Overnight cultures of the kanamycin and rifampin resistant transconjugants were spread on plates of solidified LB medium supplemented with sucrose. The $s a c B$ gene encodes levansucrase, an enzyme whose activity (in the presence of sucrose) leads to accumulation of toxic compounds in the bacterial cell [32]. Therefore, cultivation of cells carrying the functional $s a c B$ gene in medium containing sucrose results in cell lysis. This allows direct selection of $s a c B$ mutants $\left(\mathrm{Suc}^{\mathrm{r}}\right)$ (e.g. carrying inserted TEs), whose growth is not affected under these conditions. The plasmids of $100 \mathrm{Suc}^{\mathrm{r}}$ clones were analyzed for the presence of inserted TEs.

\section{DNA sequencing}

The complete nucleotide sequence of plasmid pZM3H1 was determined by the DNA Sequencing and Oligonucleotide Synthesis Laboratory (oligo.pl) at the Institute of Biochemistry and Biophysics, Polish Academy of Sciences. High-throughput sequencing of the MID-tagged shotgun plasmid-library was performed using an FLX Titanium Genome Sequencer (Roche/454 Life Sciences). Newbler de novo assembler software (Roche) was used for the sequence assembly. Final gap closure and sequence polishing were performed by capillary sequencing of PCR products using an ABI3730xl DNA Analyzer (Applied Biosystems).

Nucleotide sequences of the insertion sequences were obtained using the primer walking approach with a dye terminator sequencing kit and an automated sequencer (ABI 377 Perkin Elmer; oligo.pl).

\section{Bioinformatics}

Plasmid nucleotide sequences were analyzed using Clone Manager (Sci-Ed8) and Artemis software [33]. Similarity searches were performed using the BLAST programs [34] provided by the National Center for Biotechnology Information (NCBI) (http://blast.ncbi.nlm.nih.gov/Blast. cgi) and the PRIAM tool [35]. Comparison searches of insertion sequences were performed with ISfinder [36]. Helix-turn-helix motifs were predicted using the HELIXTURN-HELIX MOTIF PREDICTION program [37]. Phylogenetic analyses were performed using the Phylogeny Inference Package - PHYLIP v3.69 [38], applying the neighbor-joining $(\mathrm{NJ})$ algorithm with Kimura corrected distances and 1000 bootstrap replicates. DNA sequence alignments obtained with ClustalW [39] were manually refined using the T-Coffee Multiple Sequence Alignment program [40]. Highly variable portions of the alignments were eliminated by the use of G-blocks [41]. The tree was rendered with TreeView version 1.6.6. [42].

\section{Nucleotide sequence accession numbers}

The 16S rDNA sequence of Halomonas sp. ZM3 has been deposited in the NCBI database with the accession number [GenBank:JX569337]. The nucleotide sequences of plasmid pZM3H1 and insertion sequences ISHsp 1 and ISHsp 2 have been annotated and deposited with the accession numbers [GenBank:JX569338], [GenBank: JX569339] and [GenBank:JX569340], respectively.

\section{Results}

\section{Physiological characterization of the strain ZM3}

A comparative analysis of the partial $16 \mathrm{~S}$ rDNA sequence (1409 bp) of strain ZM3 revealed a high level of similarity to the corresponding sequences of several environmental isolates of Halomonas spp. (98.87\%) and Halomonas variabilis DSM $3051^{\mathrm{T}}(97.89 \%)$ isolated from the Great Salt Lake (Utah, USA) [43]. Based on this sequence homology, the strain ZM3 was classified in the genus Halomonas.

To identify specific features of Halomonas sp. ZM3 that have enabled its adaptation to the extreme environment of Zelazny Most, a complex physiological characterization of the strain was performed, including analyses of (i) temperature, $\mathrm{pH}$ and salinity tolerance, (ii) siderophore production, (iii) resistance to heavy metal ions, and (iv) PAH utilization ability. The obtained results revealed that strain ZM3 can grow in LB medium at temperatures ranging from 15 to $37^{\circ} \mathrm{C}$ (typical for mesophilic bacteria), but within a relatively narrow $\mathrm{pH}$ range of between 6 and 8 (typical for neutrophilic bacteria; [44]). Moreover, it can tolerate high salinity (up to $12 \% \mathrm{NaCl}$ in the growth medium) and the presence of high concentrations of inorganic arsenic species (MICs for $\mathrm{As}(\mathrm{III})$ and $\mathrm{As}(\mathrm{V})$ of $9 \mathrm{mM}$ and $700 \mathrm{mM}$, respectively). A low level of resistance to copper, mercury and nickel was also observed (Table 1). Analysis of the pattern of PAH utilization (five tested compounds anthracene, phenanthrene, fluoranthene, fluorene and pyrene) revealed that strain ZM3 uses phenanthrene as the sole source of carbon. Application of the universal chrome azurol S (CAS) agar plate assay demonstrated that the ZM3 strain produces high levels of ironchelating siderophores (data not shown).

The results of these physiological tests revealed that Halomonas sp. ZM3 is well adapted to inhabit the Zelazny Most mineral waste reservoir. Since many features of adaptive value are frequently determined by mobile genetic elements (e.g. widely disseminated plasmids and transposons), we analyzed the extrachromosomal DNA of this strain.

\section{General features of plasmid pZM3H1}

Halomonas sp. ZM3 carries only one extrachromosomal replicon, designated pZM3H1. DNA sequencing 
Table 1 Heavy metal resistance of Halomonas sp. ZM3

\begin{tabular}{lc}
\hline & Heavy metal resistance \\
\hline Metal & MIC \\
As (III) & $(\mathrm{mM})$ \\
$\mathrm{As}(\mathrm{V})$ & $\mathbf{9}$ \\
$\mathrm{Cd}(\mathrm{II})$ & $\mathbf{7 0 0}$ \\
$\mathrm{Co}(\mathrm{II})$ & 0.2 \\
$\mathrm{Cr}(\mathrm{VI})$ & 0.7 \\
$\mathrm{Cu}(\mathrm{II})$ & 1 \\
$\mathrm{Hg}(\mathrm{II})$ & $\mathbf{3}$ \\
$\mathrm{Ni}(\mathrm{II})$ & $\mathbf{0 . 1}$ \\
$\mathrm{Zn}(\mathrm{II})$ & $\mathbf{2}$ \\
\hline
\end{tabular}

MICs considered to represent the resistance phenotype shown in bold.

demonstrated that pZM3H1 is a circular plasmid $(31,370 \mathrm{bp})$ with a mean $\mathrm{G}+\mathrm{C}$ content (determined from its nucleotide sequence) of $57.6 \%$ (Figure 1). More detailed in silico analyses revealed that pZM3H1 carries 42 putative open reading frames (ORFs) $(73.6 \%$ of the sequence). Three of them (orf5, orf27, orf39) have no homologs in public databases, while 15 have homologs of unknown function. The functions of the remaining
ORFs were predicted from their similarities to known protein coding sequences. Features of these ORFs, including their position, transcriptional orientation, the size of the encoded proteins, and their closest known homologs, are summarized in Additional file 1: Table S1).

Further analysis of pZM3H1 revealed its modular structure. Within the plasmid genome it was possible to distinguish putative genetic modules responsible for (i) plasmid maintenance - replication (REP) and stabilization, (ii) mobilization for conjugal transfer (MOB), (iii) resistance to heavy metals, and (iv) other accessory genetic information (Figure 1).

\section{Characterization of the conserved backbone of plasmid pZM3H1}

The backbone of pZM3H1 is composed of (i) a REP module (orf1), (ii) a MOB module (orf32) and two types of stabilization module, namely (iii) PAR (orf34-orf35), encoding a partitioning system responsible for the correct distribution of plasmid molecules into daughter cells upon cell division, and (iv) TA (orf28-orf29), encoding a toxin and antitoxin involved in postsegregational elimination of plasmid-less cells (Figure 1).

The REP module of pZM3H1 carries a single ORF (orf1) encoding a predicted protein with similarities to the RepA

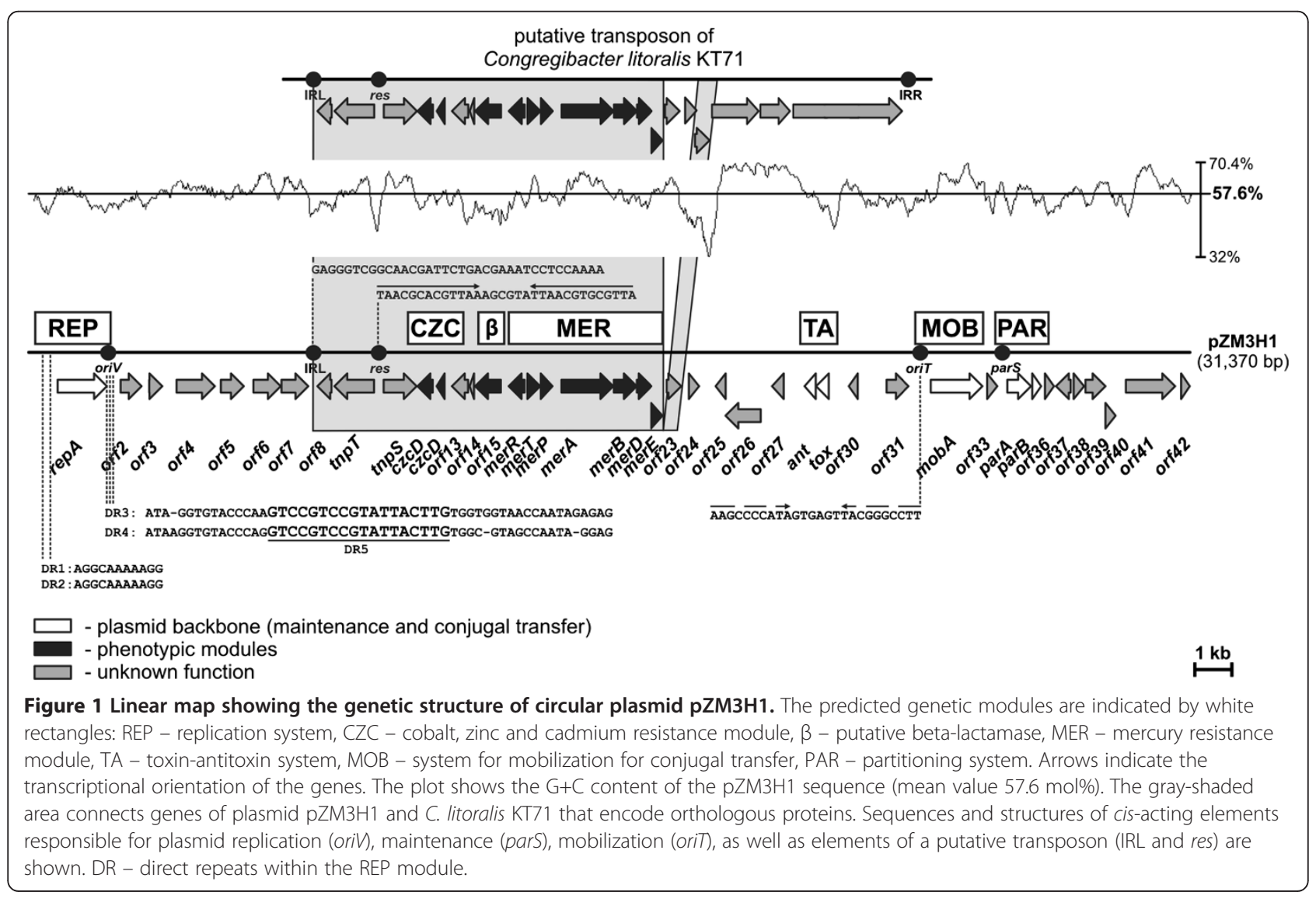


replication initiation proteins of several bacterial plasmids, including two well characterized members of the IncU incompatibility group: plasmid RA3 of Aeromonas hydrophila [45] and Rms149 of Pseudomonas aeruginosa [46]. The predicted RepA of pZM3H1 (as well as other related replication proteins) contains a putative helix-turn-helix (HTH) motif (FSYRKIATAMETSVSQVQRMLT; residues 420-441) located within the $C$-terminal part of the protein.

The putative repA gene (orfl) is bordered on both sides by stretches of A+T-rich sequence (AT content of approx. $47.5 \%$ ). Analysis of the upstream region revealed the presence of two identical direct repeat sequences (DR1, DR2; $5^{\prime}$-AGGCAAAAAGG-3/) separated by a spacer of $327 \mathrm{bp}$. The downstream region contains two long (52 and $51 \mathrm{bp}$ ), nearly identical (3 differences) direct repeats (DR3, DR4) separated by an 87 -bp spacer (Figure 1). It is noteworthy that the four $5^{\prime}$-terminal residues of DR3 are located within the RepA coding sequence. Moreover, a shorter sequence was identified 91 bp upstream of DR4 (DR5; 5'GTCCGTCCGTATTACTTG-3'), that perfectly matches the core region of the DR3 and DR4 repeats (Figure 1).

Such repeated sequences, placed downstream and upstream of the repA gene, were also identified within the REP region of the related plasmid RA3. It was demonstrated that the downstream repeats are crucial for the initiation of RA3 replication [45]. Based on the overall similarities of the REP regions, we assume that the origin of replication of pZM3H1 (oriV) is placed analogously to that of RA3, and contains the DR3, DR4 and DR5 repeats (Figure 1).

The putative PAR module of pZM3H1 is composed of two non-overlapping ORFs (orf34 and orf35; 31-bp spacer) and a centromere-like site. The orf34 encodes a putative 214-aa protein, showing significant similarity to ATPases involved in chromosome partitioning, assigned to COG1192 (cluster of orthologous group). This similarity includes the sequence KGGVGKS (residues 11-17), which matches the highly conserved canonical deviant Walker A motif KGG(T/N/V)GKT of ParA-type proteins [47]. This predicted ParA also contains an $N$-terminally located putative HTH motif (YIIGVVSQKGGVGKS TISRAVAT; residues 3-24). The orf35 encodes an 80-aa polypeptide with sequence similarity to several hypothetical proteins, whose genes are usually located downstream from predicted parA genes (i.e. orf34 homologs). This strongly suggests that orf35 encodes a ParB-type protein: another important component of plasmid partitioning systems. Careful inspection of the nucleotide sequence revealed the presence of several 7-bp imperfect inverted repeats, located close to the promoter region of the predicted par operon, which may constitute a plasmid centromere-like site (parS) (Figure 1).

TA stabilization modules usually encode two components: a toxin which recognizes a specific cellular target and an antitoxin, which counteracts the toxin. The predicted TA module of pZM3H1 fits with this scheme, since it is composed of two short non-overlapping ORFs (orf29 and orf28) separated by a 9-bp spacer. One of the ORFs (orf29) encodes a putative protein with significant sequence homology to a large family of proteins assigned to COG4679 (DUF891). These proteins, referred to as phage-related (some are encoded by bacteriophages, e.g. gp49 of phage N15), were shown to be the toxic components (RelE/ParE toxin family) of a number of TA systems [48]. The downstream gene (orf28) encodes a putative protein with substantial similarity to antitoxins classified to COG5606 and COG1396. The predicted antitoxin contains a HTH domain typical for members of the Xre/Cro protein family. Pairs of genes homologous to $\operatorname{orf} 29-\operatorname{orf} 28$ are conserved and widely distributed in bacterial genomes, including the tad-ata locus of plasmid pAMI2 of Paracoccus aminophilus JCM 7686 the archetype of this group of TA systems [48].

The next component of the pZM3H1 backbone, the MOB module, encodes a single mobilization protein (Orf32/MobA) sharing a low, but significant level of amino acid (aa) sequence homology with the Mob relaxases of pOCEGK02 from Oceanimonas sp. GK1 [GenBank: NC_016747] and broad-host-range plasmid pBBR1 of Bordetella bronchiseptica S87 [GenBank: X66730] (33\% and 31\% similarity, respectively). Detailed comparative sequence analysis of the potential Orf32/ MobA relaxase revealed the presence of several conserved motifs, which permits classification of the protein into the $\mathrm{MOB}_{\mathrm{V} 2}$ group within the $\mathrm{MOB}_{\mathrm{V}}$ family [49]. Upstream of the putative mobA (orf39) gene, an imperfect (2 mismatches) 10-bp inverted repeat sequence was identified (5'-AAGCCCCATAGTGAGTTACGGGCCTT-3'; nt position $24,073-24,098)$, whose location and structure is typical for the origin of conjugal transfer (oriT) of $\mathrm{MOB}$ systems encoding $\mathrm{MOB}_{\mathrm{V}}$ type relaxases (e.g. [50]).

\section{Analysis of the host range of pZM3H1}

To analyze the host range of the Halomonas sp. ZM3 plasmid, a mobilizable shuttle replicon pABW-ZM3H1 was constructed, containing the REP module of pZM3H1 and an E. coli-specific pMB1 (ColE1-type) replication system (see Methods for details). The obtained plasmid was introduced via conjugation into strains representing three classes of Proteobacteria: (i) Alpha- (A. tumefaciens LBA288 and P. versutus UW225), (ii) Beta- (Alcaligenes sp. LM16R), and (iii) Gammaproteobacteria (Pseudomonas spp. - strains LM5R, LM6R, LM7R, LM8R, LM11R, LM12R, LM13R, LM14R, LM15R). The plasmid was also introduced by transformation into $E$. coli BR825 (Gammaproteobacteria). Since the E. coli-specific system is not functional in any of the strains listed above (E. coli BR825 carries a mutation within the DNA polymerase I 
gene that prevents pMB1 replication), the functions required for replication of the plasmid in the tested hosts must be provided by the REP module of pZM3H1. This analysis demonstrated that $\mathrm{pABW}-\mathrm{ZM} 3 \mathrm{H} 1$ could replicate exclusively in two Pseudomonas strains (LM7R and LM12R), which indicates a relatively narrow host range.

\section{Characterization of the resistance modules}

Comparative sequence analysis revealed that a large DNA segment of pZM3H1 (10.1 kb; coordinates 7594$17,726)$ is highly conserved ( $95 \%$ nucleotide sequence identity) in the genome of Congregibacter litoralis KT71 (unfinished genome project [contig accession number GenBank:NZ_AAOA01000001]). As shown in Figure 1, the homologous $C$. litoralis region differs slightly, since it contains two additional ORFs (encoding a putative DoxDlike membrane protein and a truncated transposase) that are absent in pZM3H1 (Figure 1). Further in silico sequence analysis revealed that this region of the C. litoralis genome represents part of a putative $\mathrm{Tn} 3$ family transposon (coordinates 155,646-171,707 [GenBank: NZ_AAOA01000001]) (Figure 1), related to Tn4651 identified in plasmid pWW0 of Pseudomonas putida [51]. Plasmid pZM3H1 carries a large portion of this C. litoralis transposon (17 ORFs; orf8-orf23), although it lacks the 5.3 -kbterminal region of the element, which contains three genes coding for a putative NADP-specific glutamate dehydrogenase, a conserved membrane protein and a transposase (Figure 1). This truncated transposon contains (i-ii) two heavy metal resistance cassettes - a Co/ $\mathrm{Zn} / \mathrm{Cd}$ efflux system (orf11, orf12) and mercury resistance determinants (orf16-orf22), (iii) an ORF encoding a protein of the metallo-beta-lactamase family (orf15), (iv) a site-specific resolution system (composed of two genes tnpS and tnpT, and a putative resolution site with a hairpin structure) homologous to the MRS system of Tn4651 [51], as well as (v) four ORFs encoding hypothetical proteins with unknown functions (orf8, orf13, orf14 and orf23) (Figure 1).

The putative efflux system (CZC module; orf11, orf12) encodes a predicted $\mathrm{CzcD}$ metal transport membrane protein (a member of the cation diffusion facilitator protein family), which mediates cobalt $\left(\mathrm{Co}^{2+}\right)$, zinc $\left(\mathrm{Zn}^{2+}\right)$ and cadmium $\left(\mathrm{Cd}^{2+}\right)$ resistance (as shown in Cupriavidus metallidurans $\mathrm{CH} 34$ [52]). The mercury resistance module (MER) contains 7 ORFs (orf16-orf22) with significant levels of homology to the merRTPABDE genes, responsible for enzymatic detoxification of $\mathrm{Hg}^{2+}$ ions to the less toxic form $\mathrm{Hg}^{0}$ [53]. The key enzymes in this mercury resistance system are (i) organomercurial lyase (MerB) effectively performs hydrolysis of stable mercury-carbon bonds, and (ii) mercuric reductase (MerA) - reduces $\mathrm{Hg}^{2+}$ to $\mathrm{Hg}^{0}$ (metallic mercury) in a process that involves hydride transfer from the electron carrier NADPH to flavin. Three other important components are (i) two transcriptional regulatory proteins (MerR and MerD), (ii) two mercury ion transport proteins (MerT and MerP), and (iii) an accessory membrane protein (MerE) [53] (Figure 1 and Additional file 1: Table S1).

To investigate whether the analyzed resistance cassettes are functional, plasmid pBBR-ZM3CZCMER was constructed by inserting the orf11-orf23 gene cluster of pZM3H1 (contains the CZC and MER modules) into broad-host-range (BHR) mobilizable vector pBBR-MCS2 (see Methods for details). Since we were unable to remove (by incompatibility) plasmid pZM3H1 from its natural host (Halomonas sp. ZM3), the obtained plasmid pBBR-ZM3CZCMER was introduced (by conjugation or transformation) into Pseudomonas spp. LM7R and LM12R (pZM3H1 was shown to replicate in both strains) and E. coli TG1 (three members of Gammaproteobacteria), as well as A. tumefaciens LBA288 (Alphaproteobacteria). The resistance phenotypes of the obtained transconjugants and the wild-type strains were then tested by determination of the minimum inhibitory concentrations (MICs) of $\mathrm{Cd}, \mathrm{Co}, \mathrm{Zn}$ and $\mathrm{Hg}$ salts in liquid culture (Figure 2).

This analysis revealed that introduction of pBBRZM3CZCMER into strain LM7R resulted in a significant increase in the MICs of cobalt (6-fold) and zinc (3-fold), which indicates resistance. In contrast, the level of tolerance to mercury was not changed (Figure 2). Different results were obtained with the transconjugants of strains LM12R and LBA288, which exhibited resistance to mercury (MIC increases of 1.5- and 3-fold, respectively), but not to cobalt or zinc. Interestingly, none of the tested strains was resistant to cadmium. Introduction of the plasmid pBBR-ZM3CZCMER into E. coli TG1 did not result in cobalt or mercury resistance; however, an unexpected increase in sensitivity to zinc was observed (Figure 2).

Besides the CZC and MER modules, plasmid pBBRZM3CZCMER also carries orf15 encoding a protein related to metallo-beta-lactamases, many of which confer resistance to beta-lactam antibiotics, e.g. [54]. Therefore, we tested whether the pBBR-ZM3CZCMER-containing strains (LM7R, LM12R, LBA288, TG1) acquired resistance to antibiotics representing three classes of beta-lactams: (i) ampicillin (penicillins), (ii) ceftazidime (cefalosporins) and (iii) meropenem (carbapenems). The MICs, determined by Epsilometer tests, revealed no resistance phenotype, indicating that Orf15 protein does not exhibit beta-lactamase activity in these strains.

\section{Identification and characterization of transposable elements (TEs)}

For the identification of functional TEs of Halomonas sp. ZM3 we employed the mobilizable BHR trap plasmid pMAT1, carrying the $s a c B$ cassette, which enables 


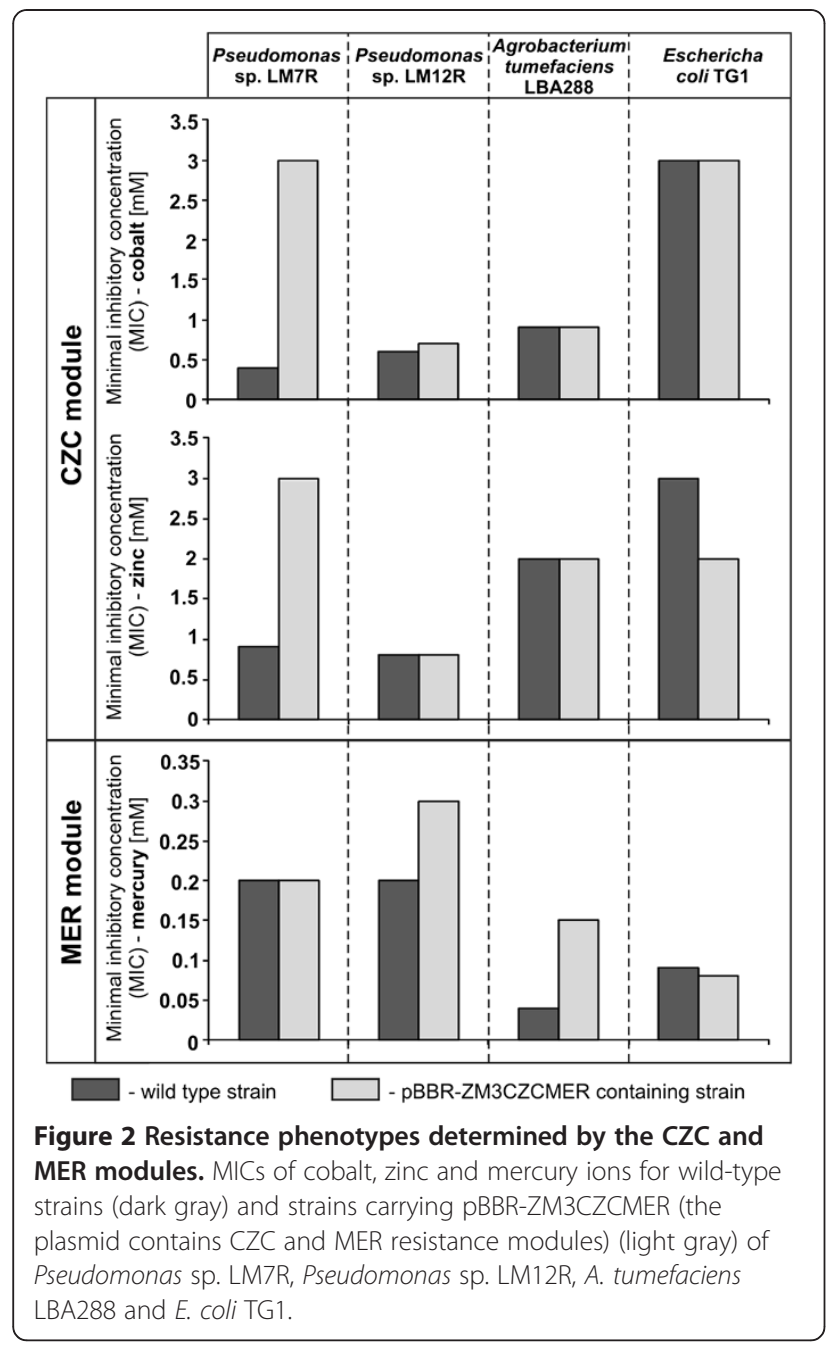

positive selection of transposition events [20]. A pool of putative transposition mutants was collected and analyzed as described in Methods. From this set of mutants, two classes of pMAT1 derivatives were identified, containing inserted elements of respective sizes $1 \mathrm{~kb}$ and 1.5 $\mathrm{kb}$, which is typical for the majority of insertion sequences (ISs). DNA sequencing and comparison of the obtained nucleotide sequences (NCBI and ISfinder databases) revealed that the identified elements were novel insertion sequences, designated ISHsp 1 and ISHsp2.

ISHsp1 carries identical terminal inverted repeat sequences (IRs) of $15 \mathrm{bp}$ at both ends (Figure 3). Transposition of the element into the $s a c B$ cassette of pMAT1 resulted in duplication of a short (6 bp) target sequence $\left(5^{\prime}\right.$-TACTTA-3') to form direct repeats (DRs) (Figure 3). Within the 1518-bp-long sequence of ISHsp1 (G+C content $-56.7 \%$ ) only one ORF was identified (nt position 113-1495), encoding a putative protein (460 aa; 52.7 $\mathrm{kDa}$ ) with $93 \%$ sequence identity to the transposase of ISMaq6 of Marinobacter aquaeolei VT8 [GenBank: ABM18542]. Both elements (ISHsp1 and ISMaq6) also show high overall similarity (89\%) of their nucleotide sequences.

The predicted transposase of ISHsp1 contains N2, N3 and $\mathrm{C} 1$ regions, including three acidic residues (DDE motif), that are highly conserved in the catalytic domains of transposases of bacterial TEs and retrovirus integrases [55]. As shown in Figure 3, the sequence of this motif is in relatively good agreement with the DDE consensus for transposases of the IS5 group of the IS5 family; however, the distance between the N3 and $\mathrm{C} 1$ regions (69 aa) is significantly longer than that of the consensus sequence ( $45 \mathrm{aa})$.

The other captured element, ISHsp2 (1078 bp; G+C content $-53.7 \%$ ), contains non-identical terminal IRs of $26 \mathrm{bp}$ (10 mismatches) and two non-overlapping ORFs (orf1 and orf2), encoding putative proteins of 132 aa

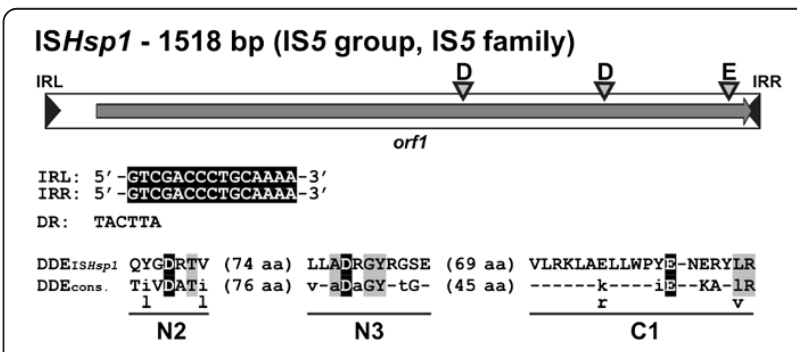

ISHsp2 - 1078 bp (IS630 family)

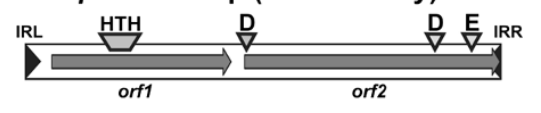

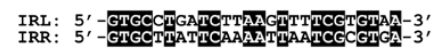

DR: TTAA

HTH: HTINQISQILEVRRDAVSRWLK

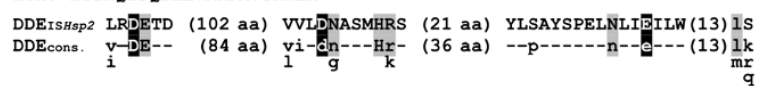
N2

N3

C1

Figure 3 Genetic organization of the insertion sequences ISHsp1 and ISHsp2. Inverted repeats (IRL - left IR; IRR - right IR) flanking ISs are marked by black arrowheads. Predicted coding regions are represented by gray arrows indicating the direction of transcription. The location of the DNA-binding domain $(\mathrm{HTH})$ and the DDE motifs are marked. Alignments of the inverted terminal repeats and the sequences of the duplicated direct repeats (DR) are presented beneath each insertion sequence diagram. Identical nucleotides within the IRL and IRR of each IS are indicated by white text against a black background. The amino acid sequences of the predicted N2, N3, and C1 regions, and DDE motifs of the putative transposases encoded by ISHsp1 and ISHsp2 are compared with appropriate family- and group-specific consensus sequences. In the consensus sequences, uppercase letters indicate conservation within the family or group, while lowercase letters denote predominant amino acids, and dashes mark the non-conserved residues. Residues forming the DDE motif are indicated by white text on a black background. The residues conserved in the domains of the analyzed transposases and the consensus sequences are presented against a gray background. The numbers in parentheses show the distances (in amino acids) between the conserved domains. 
$(15.2 \mathrm{kDa})$ and 192 aa $(22.2 \mathrm{kDa})$, respectively (Figure 3). Within orf1 (nt position 446), a putative -1 frameshift motif was identified (5'-GAAAAAAAAA-3') in the loop of a predicted mRNA stem-loop structure. This motif most probably promotes a programmed translational frameshift, which leads to the formation of a functional fusion (Orf1+Orf2) transposase (as shown e.g. for IS1 and IS3 family members [56,57]). The putative proteins encoded by the individual ORFs of ISHsp 2 carry a potential HTH DNA-binding motif (Orf1) and a complete DDE motif (Orf2) - typical for the IS630 family. Both motifs are also present within the predicted trans-frame transposase (337 aa; $40 \mathrm{kDa}$ ) generated by translational slippage. The fusion transposase shows the highest level of aa sequence similarity (44\%) with the fusion transposase of ISVsa 8 an element present in 27 copies in chromosomes I and II of Aliivibrio salmonicida LFI1238 [58].

Based on the results of the comparative analysis, ISHsp1 and ISHsp 2 have been classified as novel members of the IS5 (IS5 group) and IS630 families, respectively.

\section{Copy number of selected genes of the identified MGEs}

To determine the copy number of the identified ISs, as well as the CZC and MER modules of pZM3H1 in the Halomonas sp. ZM3 genome, DNA hybridization analysis was performed. PCR-amplified digoxygenin-labeled internal fragments of the merA gene (orf19), $c z c D$ gene (orf11-12), ISHsp1 and ISHsp2 (primers used are given in Methods) were used to probe Southern blots of total Halomonas sp. ZM3 DNA digested with restriction enzymes (selected so that the number of DNA fragments hybridizing with the probes was equivalent to the minimum number of copies of a given gene/element). Using this method, single copies of the CZC and MER modules were identified in the ZM3 genome (within plasmid pZM3H1), while four and two copies of the insertion sequences ISHsp 1 and ISHsp 2 were detected, respectively (data not shown).

\section{Discussion}

Groundwater from the Lubin-Glogow mines (Copper Mine District, Poland), that has various uses including the flotation of sulfides during ore processing, contains sodium and chlorine ions at high concentrations, which results in elevated salinity of the deposits in the Zelazny Most waste reservoir. These conditions favor the expansion of halophilic microorganisms, one of which (Halomonas sp. ZM3) was analyzed in this study. Strain ZM3 is well adapted to the harsh environment of Zelazny Most, since it is hyper-resistant to inorganic arsenic species $\mathrm{As}(\mathrm{III})$ and $\mathrm{As}(\mathrm{V})$, and shows elevated resistance to highly toxic ions of copper, mercury and nickel. Moreover, it is able to utilize phenanthrene (composed of three fused benzene rings), which makes it a good candidate for bioremediation of PAH-contaminated hypersaline environments. The strain ZM3 is also an efficient siderophore producer. Such metal chelating compounds have been shown to complex iron and other metals, and also mobilize chemical elements from minerals (e.g. hausmannite [59]), and so may play a significant role in the redistribution of elements in the Zelazny Most environment.

The present study was focused on mobile genetic elements (plasmid and TEs) of Halomonas sp. ZM3. Our analysis revealed that the ZM3 strain carries only one extrachromosomal replicon (plasmid pZM3H1; 31,370 $\mathrm{bp}$ ), whose replication system shows similarity to the REP modules of several plasmids classified within the IncU incompatibility group. Although this group contains several broad-host-range conjugative plasmids responsible for the dissemination of antibiotic resistance determinants (e.g. [60]), there is a dearth of knowledge about IncU replicons. To better define this group, we performed comprehensive BLAST searches of the NCBI database, which identified 27 replicons encoding homologous Rep proteins (E-value $<1 \times 10^{-20}$ ) with amino acid sequence similarity levels of $\geq 27 \%$.

Phylogenetic analysis of the IncU plasmids (performed on the basis of the Rep protein sequences) revealed the presence of two subgroups, comprised of 12 and 13 replicons, which clearly correspond to the Gramnegative (Proteobacteria) and Gram-positive (Firmicutes) hosts, respectively. As shown in Figure 4, the phylogenetic distance of the pZM3H1 Rep reflects its weak relationship with Rep proteins of Gram-negative bacteria. This suggests that the replication system of pZM3H1 may be considered as an archetype of a novel subgroup of IncU-like replicons (Figure 4).

The divergence of the REP module may be reflected by the relatively narrow host range (NHR) of pZM3H1. Besides the native strain ZM3, this plasmid was shown to replicate in only two (of nine tested) strains of Pseudomonas (isolated from the Lubin copper mine). Many of the analyzed strains lack their own plasmids, so the failure to obtain transconjugants did not result from incompatibility between the incoming and residing replicons. Therefore, it may be hypothesized that the initiation of pZM3H1 replication requires specific cellular factors present only in some strains or species of the genus Pseudomonas or Halomonas.

Plasmid pZM3H1 contains a predicted MOB module, which suggests that it may be mobilized for conjugal transfer. It has recently been demonstrated that the host range of MOB systems can be wider than the replication systems of the plasmids they carry. Thus, NHR mobilizable plasmids may be considered as efficient carrier molecules, which act as natural suicide vectors promoting the spread of diverse genetic information (e.g. resistance transposons) among evolutionarily-distinct 


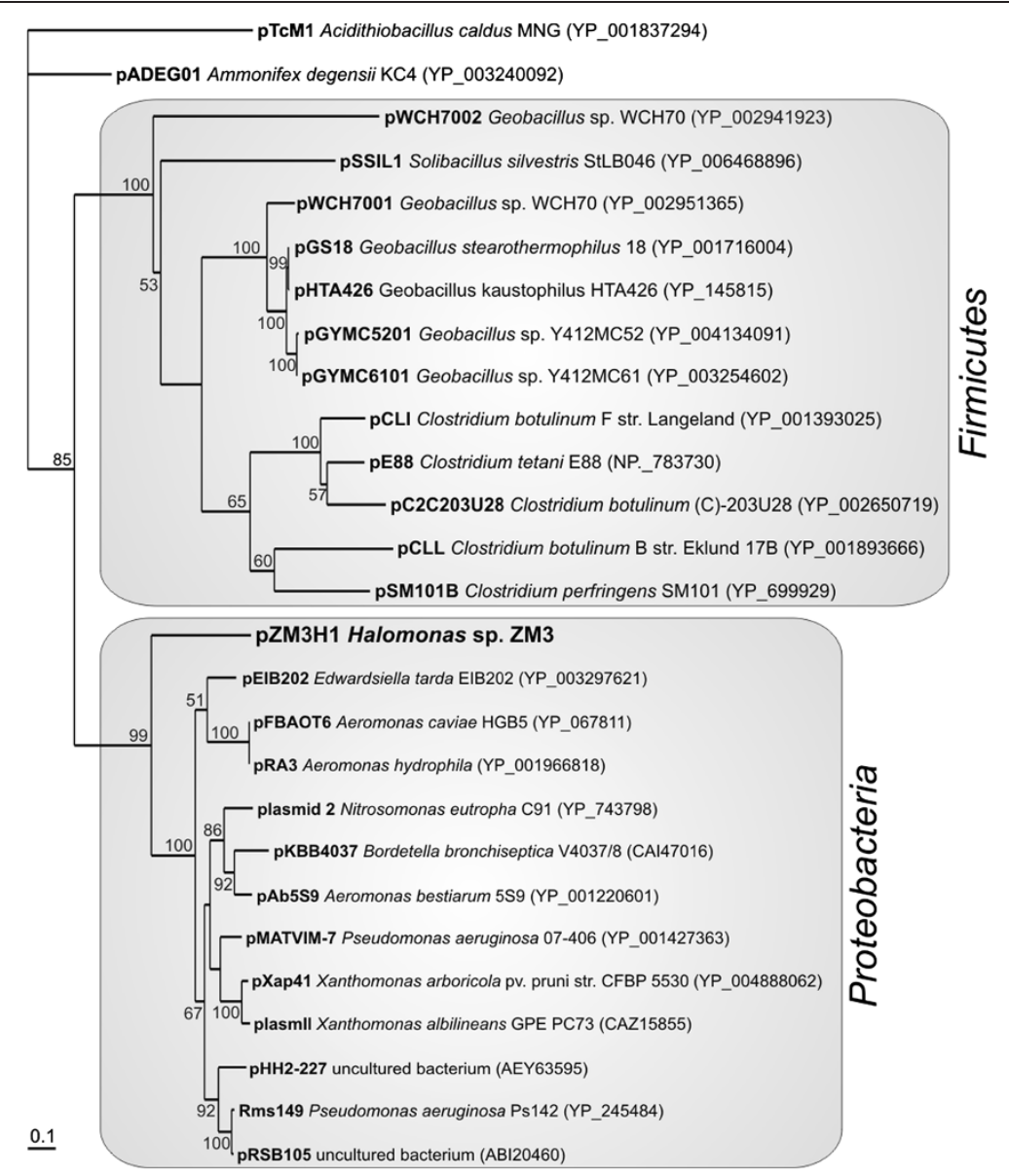

Figure 4 Phylogenetic tree of the replication initiation protein (Rep) of IncU-family plasmids. The analysis was based on 27 sequences (from fully sequenced plasmids) and 217 amino acid positions. The unrooted tree was constructed using the neighbor-joining algorithm with Kimura corrected distances, and statistical support for the internal nodes was determined by 1000 bootstrap replicates. Values of $>50 \%$ are shown. Accession numbers of the protein sequences used for the phylogenetic analysis are given in parentheses.

bacterial species [61]. Plasmid pZM3H1, despite its narrow host range, may therefore play an important role in horizontal dissemination of genetic modules conferring heavy metal resistance phenotypes.

The resistance cassette of pZM3H1, composed of MER and CZC genetic modules, is part of a large truncated Tn3 family transposon. It is well known that mer operons mediate detoxification of mercury compounds, while $c z c D$ genes mediate low level $\mathrm{Zn}^{2+}, \mathrm{Co}^{2+}$ and $\mathrm{Cd}^{2+}$ resistance (higher level resistance is usually determined by the $c z c C B A$ system) [62]. Both modules are widely disseminated in bacterial genomes and frequently occur on plasmids and transposons (e.g. $[53,63])$.

Unexpectedly, the introduction of these resistance modules into two Pseudomonas spp. strains (LM7R and LM12R - both able to maintain pZM3H1) produced completely different phenotypes. Strain LM7R (containing $\mathrm{MER}+\mathrm{CZC}$ ) gained resistance to zinc and cobalt, but not mercury, whereas LM12R acquired only mercury resistance (Figure 2). Moreover, neither of the strains was resistant to cadmium. This finding demonstrated that the phenotype determined by plasmid pZM3H1 is highly dependent on the host strain. The host specificity of resistance phenotypes generated by two related $c z c D$ modules of Staphylococcus aureus and Thermus thermophilus was also described by Nies [62]. The results revealed that the former is involved in zinc and cobalt resistance, while the latter mediates zinc and cadmium (but not cobalt) resistance.

In another strand of the present study, the trap plasmid pMAT1 was employed to identify functional transposable elements of Halomonas sp. ZM3. Using the sacB positive selection strategy, we were unable to "capture" any resistance transposons. The only identified elements were two insertion sequences: ISHsp1 (IS5 group of IS5 family) and ISHsp2 (IS630 family). Both elements are present in more than one copy in the ZM3 genome, and so they may potentially form composite transposons.

ISHsp1 is most closely related to ISMaq6 of $M$. aquaeolei VT8 (89\% nucleotide sequence identity). 
Members of the genera Marinobacter and Halomonas are widely distributed in many environments. These bacteria are usually isolated from the same habitats, including oceans and seas, saline soils, marine snow, hot springs and volcanic basalts [64], which may favor horizontal gene transfer between them (several strains of Marinobacter spp. have been isolated from the Zelazy Most reservoir; unpublished results).

The second "captured" element, ISHsp2, was classified within the IS630/Tc1 superfamily, which is comprised of promiscuous TEs found in both prokaryotes and eukaryotes [65]. ISHsp 2 carries two ORFs encoding the $N$ - and $C$-terminal parts of the transposase, respectively. Therefore, generation of the complete functional enzyme requires ribosomal frame-shifting: a phenomenon that plays an important role in regulating the frequency of transposition of some ISs (e.g. [56,57]). The fusion transposase of ISHsp2 exhibits only a moderate level of amino acid sequence homology to transposases of the IS630 family. Moreover, transposition of the IS generates 4-bp-long DRs (5'-TTAA-3'), while other related elements duplicate only the $5^{\prime}-\mathrm{TA}-3^{\prime}$ dinucleotide. These divergent features indicate that ISHsp 2 represents a distinct member of the IS630 family.

\section{Conclusions}

Bacteria of the genus Halomonas are "opportunitrophic" microbes, since they are generalists that employ a strategy of acquiring and maintaining a broad and diverse metabolic potential in order to exploit changeable environmental resources [64]. Such strains may find application in biotechnology and bioremediation, so it is extremely important to characterize their metabolic potential, as well as their mobile genetic elements, which facilitate horizontal gene transfer and increase the fitness of their hosts in extreme environments.

The overall characterization of Halomonas sp. ZM3 has provided information concerning genus- (elevated salinity tolerance), as well as strain-specific physiological features (i.e. arsenic, copper, mercury and nickel resistance, and phenanthrene utilization ability), that enable the survival of ZM3 in the highly contaminated environment of Zelazny Most.

Special attention was given to plasmid pZM3H1, carrying heavy metal resistance determinants. This plasmid is unique among the elements identified in this genus (sequences from 8 Halomonas spp. genome projects), which suggests its relatively recent acquisition.

Characterization of the ZM3 plasmid as well as two novel transposable elements increase current knowledge concerning the diversity of mobile DNA of bacteria of the family Halomonadaceae. Moreover, the identified elements and their individual genetic modules may be used to construct specific tools for the genetic analysis of Halomonas spp.

\section{Additional file}

Additional file 1: Table S1. Description of ORFs located within plasmid pZM3H1 of Halomonas sp. ZM3. The table indicates characteristic features of distinguished ORFs, including their position, transcriptional orientation, the size of the encoded proteins, and their closest known homologs.

\section{Abbreviations}

BHR: Broad host range; COG: Cluster of orthologous group; CZC: Cobalt, Zinc and Cadmium Resistance Determinant; DR: Direct repeat sequences; DUF: Domain of unknown function; HTH: Helix turn helix; IS: Insertion sequence; LB: Lysogeny broth; MER: Mercury resistance determinant; MGE: Mobile genetic elements; MIC: Minimum inhibitory concentration; MOB: Mobilization for conjugal transfer; NADP: Nicotinamide adenine dinucleotide phosphate, ncbi, national center for biotechnology information; NHR: Narrow host range; ORF: Open reading frame; PAH: Polycyclic aromatic hydrocarbons; PAR: Partitioning; REP: Replication; TA: Toxin-Antitoxin; TE: Transposable element.

\section{Competing interests}

The authors declare that they have no competing interests.

\section{Authors' contributions}

LD and AP performed the main laboratory experiments, LD performed bioinformatic analyses, analyzed the data and coordinated the project, RM isolated and characterized the ZM3 strain, JB and MS identified and analyzed transposable elements, MS constructed mini-derivatives of plasmid pZM3H1, DB designed the project and supervised the work, LD and DB wrote the manuscript. All authors read and approved the final version of the manuscript.

\section{Acknowledgements}

We acknowledge A Sklodowska for providing the ZM3 strain. This work was supported by the Ministry of Science and Higher Education, Poland (grant N N303 579238).

\section{Author details}

${ }^{1}$ University of Warsaw, Faculty of Biology, Institute of Microbiology, Department of Bacterial Genetics, Miecznikowa 1, 02-096, Warsaw, Poland. ${ }^{2}$ University of Warsaw, Faculty of Biology, Laboratory of Environmental Pollution Analysis, Miecznikowa 1, 02-096, Warsaw, Poland.

Received: 4 January 2013 Accepted: 8 March 2013

Published: 14 March 2013

\section{References}

1. Piestrzyński A, Bochajczuk J: Monografia KGHM Polska Miedz S.A. Lubin: "Cuprum" Sp. z o.o; 1996

2. Sun YZ: Distribution of selected elements and PAH in freshly deposited sediments of waste water streams from Lubin District, southwest Poland. Environ Geochem Health 1999, 21:141-155.

3. Lasocki S, Antoniuk J, Moscicki J: Environmental protection problems in the vicinity of the Zelazny Most flotation wastes depository in Poland. J Environ Sci Health, Part A: Tox Hazard Subst Environ Eng 2003, 38:1435-1443

4. Bocheńska T, Butra J, Kalisz M: Impact of the mining industry on the water environment in the Lubin-Głogów Copper Region (LGOM). In Proceedings of the 7th International Mine Water Association Congress; Ustroń. 2000:68-80.

5. de la Haba RR, Arahal DR, Márquez MC, Ventosa A: Phylogenetic relationships within the family Halomonadaceae based on comparative $23 \mathrm{~S}$ and 16S rRNA gene sequence analysis. Int J Syst Evol Microbiol 2010, 60:737-748

6. Llamas I, del Moral A, Martínez-Checa F, Arco Y, Arias S, Quesada E: Halomonas maura is a physiologically versatile bacterium of both ecological and biotechnological interest. Antonie Van Leeuwenhoek 2006, 89:395-403. 
7. Ma Y, Galinski EA, Grant WD, Oren A, Ventosa A: Halophiles 2010: life in saline environments. App/ Environ Microbiol 2010, 76:6971-6981.

8. Tan D, Xue YS, Aibaidula G, Chen GQ: Unsterile and continuous production of polyhydroxybutyrate by Halomonas TD01. Biorescour Technol 2011, 102:8130-8136

9. Schwibbert K, Marin-Sanguino A, Bagyan I, Heidrich G, Lentzen G, Seitz H, Rampp M, Schuster SC, Klenk HP, Pfeiffer F, Oesterhelt D, Kunte HJ: A blueprint of ectoine metabolism from the genome of the industrial producer Halomonas elongata DSM 2581 T. Environ Microbio/ 2011, 13:1973-1994.

10. Vargas C, Tegos G, Vartholomatos G, Drainas C, Ventosa A, Nieto JJ: Genetic organization of the mobilization region of the plasmid pHE1 from Halomonas elongata. Syst Appl Microbiol 1999, 22:520-529.

11. Vargas C, Tegos G, Drainas C, Ventosa A, Nieto JJ: Analysis of the replication region of the cryptic plasmid pHE1 from the moderate halophile Halomonas elongata. Mol Gen Genet 1999, 261:851-861.

12. Mobberley JM, Authement RN, Segall AM, Paul JH: The temperate marine phage PhiHAP-1 of Halomonas aquamarina possesses a linear plasmidlike prophage genome. J Virol 2008, 82:6618-6630.

13. D'Hugues P, Norris PR, Hallberg KB, Sánchez F, Langwaldt J, Grotowski A, Chmielewski T, Groudev S: Bioshale consortium: bioshale FP6 European project: exploiting black shale ores using biotechnologies? Miner Eng 2008, 21:111-120.

14. Gibson TJ: Studies on Epstein-Barr genome. PhD thesis. University of Cambridge; 1984.

15. Ludtke DN, Eichorn BG, Austin SJ: Plasmid-partition functions of the P7 prophage. J Mol Biol 1989, 209:393-406.

16. Hooykaas PJJ, den Dulk-Ras H, Schilperoort RA: Molecular mechanism of Ti plasmid mobilization by R plasmids: isolation of Ti plasmids with transposon insertions in Agrobacterium tumefaciens. Plasmid 1980, 4:64-75.

17. Bartosik D, Baj J, Plasota M, Piechucka E, Wlodarczyk M: Analysis of Thiobacillus versutus pTAV1 plasmid functions. Acta Microbiol Pol 1993, 39:5-11.

18. Bartosik D, Bialkowska A, Baj J, Wlodarczyk M: Construction of mobilizable cloning vectors derived from pBGS18 and their application for analysis of replicator region of a pTAV202 mini-derivative of Paracoccus versutus pTAV1 plasmid. Acta Microbiol Pol 1997, 46:387-392.

19. Kovach ME, Phillips RW, Elzer PH, Roop RM II, Petersen K: pBBR1MCS: a broad-host-range cloning vector. Biotechniques 1994, 16:800-802.

20. Szuplewska M, Bartosik D: Identification of a mosaic transposable element of Paracoccus marcusii composed of insertion sequence ISPmar4 (ISAs1 family) and an IS1247a-driven transposable module (TMo). FEMS Microbiol Lett 2009, 292:216-221.

21. Sambrook J, Russell DW: Molecular Cloning: a Laboratory Manual. 3rd edition. New York, NY: Cold Spring Harbor Laboratory Press; 2001

22. Hartmans S, Smits JP, Van der Werf MJ, Volkering F, De Bont JAM: Metabolism of styrene oxide and 2-phenylethanol in the styrene-degrading Xanthobacter strain 124X. Appl Environ Microbiol 1989, 55:2850-2855.

23. Kiyohara H, Nagao K, Yana K: Rapid screen for bacteria degrading waterinsoluble, solid hydrocarbons on agar plates. Appl Environ Microbiol 1982, 43:454-457.

24. Ahn Y, Sanseverino J, Sayler GS: Analyses of polycyclic aromatic hydrocarbon-degrading bacteria isolated from contaminated soils. Biodegradation 1999, 10:149-157.

25. Abou-Shanab RA, van Berkum P, Angle JS: Heavy metal resistance and genotypic analysis of metal resistance genes in gram-positive and gramnegative bacteria present in Ni-rich serpentine soil and in the rhizosphere of Alyssum murale. Chemosphere 2007, 68:360-367.

26. Nieto JJ, Ventosa A, Ruiz-Berraquero F: Susceptibility of halobacteria to heavy metals. App/ Environ Microbiol 1987, 53:1199-1202.

27. Schwyn B, Neilands JB: Universal chemical assay for the detection and determination of siderophores. Anal Biochem 1987, 160:47-56.

28. Gathogo EW, Waugh AC, Peri N, Redpath MB, Long PF: Colony PCR amplification of actinomycete DNA. J Antibiot 2003, 56:423-424.

29. Lane DJ: 16S/23S rRNA sequencing. In Nucleic Acid Techniques in Bacterial Systematics. Edited by Stackebrandt E, Goodfellow M. New York, NY: Wiley; 1991:115-175.

30. Kushner SR: An improved method for transformation of E. coli with ColE1 derived plasmids. In Genetic Engineering. Edited by Boyer HB, Nicosia S. Amsterdam: Elsevier/North-Holland; 1978:17-23.

31. Bartosik D, Szymanik M, Wysocka E: Identification of the partitioning site within the repABC-type replicon of the composite Paracoccus versutus plasmid pTAV1. J Bacterio/ 2001, 183:6234-6243.
32. Gay P, Le Coq D, Steinmetz M, Berkelman T, Kado Cl: Positive selection procedure for entrapment of insertion sequence elements in gramnegative bacteria. J Bacterio/ 1985, 164:918-921

33. Carver T, Berriman M, Tivey A, Patel C, Bö hme U, Barrell BG, Parkhill J, Rajandream MA: Artemis and ACT: viewing, annotating and comparing sequences stored in a relational database. Bioinformatics 2008, 24:2672-2676.

34. Altschul SF, Madden TL, Schaffer AA, Zhang J, Zhang Z, Miller W, Lipman DJ: Gapped BLAST and PSI-BLAST: a new generation of protein database search programs. Nucleic Acids Res 1997, 25:3389-3402

35. Claudel-Renard C, Chevalet C, Faraut T, Kahn D: Enzyme-specific profiles for genome annotation: PRIAM. Nucleic Acids Res 2003, 31:6633-6639.

36. Siguier P, Perochon J, Lestrade L, Mahillon J, Chandler M: ISfinder: the reference centre for bacterial insertion sequences. Nucleic Acids Res 2006, 34:32-36.

37. Dodd IB, Egan JB: Improved detection of helix-turn-helix DNA-binding motifs in protein sequences. Nucleic Acids Res 1990, 18:5019-5026.

38. Felsenstein J: Mathematics vs evolution: mathematical evolutionary theory. Science 1989, 246:941-942.

39. Chenna R, Sugawara H, Koike T, Lopez R, Gibson TJ, Higgins DG, Thompson JD: Multiple sequence alignment with the Clustal series of programs. Nucleic Acids Res 2003, 31:3497-3500.

40. Notredame C, Higgins DG, Heringa J: T-coffee: a novel method for fast and accurate multiple sequence alignment. J Mol Biol 2000, 302:205-217.

41. Talavera G, Castresana J: Improvement of phylogenies after removing divergent and ambiguously aligned blocks from protein sequence alignments. Syst Biol 2007, 56:564-577.

42. Page RDM: Tree view: an application to display phylogenetic trees on personal computers. Comput Appl Biosci 1996, 12:357-358.

43. Arahal DR, Ludwig W, Schleifer KH, Ventosa A: Phylogeny of the family Halomonadaceae based on $23 \mathrm{~S}$ and 165 rDNA sequence analyses. Int J Syst Evol Microbiol 2002, 52:241-249.

44. Slonczewski JL, Fujisawa M, Dopson M, Krulwich TA: Cytoplasmic pH measurement and homeostasis in bacteria and archaea. Adv Microb Physiol 2009, 55:1-79.

45. Kulinska A, Czeredys M, Hayes F, Jagura-Burdzy G: Genomic and functional characterization of the modular broad-host-range RA3 plasmid, the archetype of the IncU group. Appl Environ Microbiol 2008, 74:4119-4132.

46. Haines AS, Jones K, Cheung M, Thomas CM: The IncP-6 plasmid Rms149 consists of a small mobilizable backbone with multiple large insertions. J Bacteriol 2005, 187:4728-4738.

47. Ramakrishnan C, Dani VS, Ramasarma T: A conformational analysis of Walker motif $A$ [GXXXXGKT(S)] in nucleotide-binding and other proteins. Protein Eng 2002, 15:783-798.

48. Dziewit L, Jazurek M, Drewniak L, Baj J, Bartosik D: The SXT conjugative element and linear prophage N15 encode toxin-antitoxin-stabilizing systems homologous to the tad-ata module of the Paracoccus aminophilus plasmid pAMI2. J Bacteriol 2007, 189:1983-1997.

49. Garcillan-Barcia MP, Francia MV, de la Cruz F: The diversity of conjugative relaxases and its application in plasmid classification. FEMS Microbiol Rev 2009, 33:657-687.

50. Szpirer CY, Faelen M, Couturier M: Mobilization function of the pBHR1 plasmid, a derivative of the broad-hostrange plasmid pBBR1. J Bacteriol 2001, 183:2101-2110.

51. Genka H, Nagata Y, Tsuda M: Site-specific recombination system encoded by toluene catabolic transposon Tn4651. J Bacteriol 2002, 184:4757-4766.

52. Anton A, Weltrowski A, Haney CJ, Franke S, Grass G, Rensing C, Nies DH: Characteristics of zinc transport by two bacterial cation diffusion facilitators from Ralstonia metallidurans $\mathrm{CH} 34$ and Escherichia coli. J Bacteriol 2004, 186:7499-7507.

53. Silver S, Phung LT: A bacterial view of the periodic table: genes and proteins for toxic inorganic ions. J Ind Microbiol Biotechnol 2005, 32:587-605.

54. Widmann M, Pleiss J, Oelschlaeger P: Systematic analysis of metallo- $\beta$ -lactamases using an automated database. Antimicrob Agents Chemother 2012, 56:3481-3491.

55. Chandler M, Mahillon J: Insertion sequences revisited. In Mobile DNA II. Edited by Craig NL, Craigie M, Gellert M, Lambovitz AM. Washington, DC American Society for Microbiology; 2002:305-366.

56. Escoubas JM, Prere MF, Fayet O, Salvignol I, Galas D, Zerbib D, Chandler M: Translational control of transposition activity of the bacterial insertion sequence IS1. EMBO J 1991, 10:705-712. 
57. Zheng J, McIntosh MA: Characterization of IS1221 from Mycoplasma hyorhinis: expression of its putative transposase in Escherichia coli incorporates a ribosomal frameshift mechanism. Mol Microbiol 1995, 16:669-685.

58. Hjerde E, Lorentzen MS, Holden MT, Seeger K, Paulsen S, Bason N, Churcher C, Harris D, Norbertczak H, Quail MA, Sanders S, Thurston S, Parkhill J, Willassen NP, Thomson NR: The genome sequence of the fish pathogen Aliivibrio salmonicida strain LFI1238 shows extensive evidence of gene decay. BMC Genomics 2008, 9:616.

59. Peña J, Duckworth OW, Bargar JR, Sposito G: Dissolution of hausmannite $\left(\mathrm{Mn}_{3} \mathrm{O}_{4}\right)$ in the presence of the trihydroxamate siderophore desferrioxamine B. Geochem Cosmochem Acta 2007, 71:5661-5671.

60. Schlüter A, Szczepanowski R, Kurz N, Schneiker S, Krahn I, Pühler A: Erythromycin resistance-conferring plasmid pRSB105, isolated from a sewage treatment plant, harbors a new macrolide resistance determinant, an integron-containing Tn402-like element, and a large region of unknown function. Appl Environ Microbiol 2007, 73:1952-1960.

61. Smorawinska M, Szuplewska M, Zaleski P, Wawrzyniak P, Maj A, Plucienniczak A, Bartosik D: Mobilizable narrow host range plasmids as natural suicide vectors enabling horizontal gene transfer among distantly related bacterial species. FEMS Microbiol Lett 2012, 326:76-82.

62. Nies DH: Efflux-mediated heavy metal resistance in prokaryotes. FEMS Microbiol Rev 2003, 27:313-339.

63. Barkay T, Miller SM, Summers AO: Bacterial mercury resistance from atoms to ecosystems. FEMS Microbiol Rev 2003, 27:355-384.

64. Singer E, Webb EA, Nelson WC, Heidelberg JF, Ivanova N, Pati A, Edwards KJ Genomic potential of Marinobacter aquaeolei, a biogeochemical "opportunitroph". Appl Environ Microbiol 2011, 77:2763-2771.

65. Tsuge $Y$, Ninomiya K, Suzuki N, Inui M, Yukawa H: A new insertion sequence, IS14999, from Corynebacterium glutamicum. Microbiology 2005, 151:501-508.

doi:10.1186/1471-2180-13-59

Cite this article as: Dziewit et al:: Characterization of Halomonas sp. ZM3 isolated from the Zelazny Most post-flotation waste reservoir, with a special focus on its mobile DNA. BMC Microbiology 2013 13:59.

\section{Submit your next manuscript to BioMed Central and take full advantage of:}

- Convenient online submission

- Thorough peer review

- No space constraints or color figure charges

- Immediate publication on acceptance

- Inclusion in PubMed, CAS, Scopus and Google Scholar

- Research which is freely available for redistribution 